\title{
Legal Issues in Medical Practice in Malaysia
}

\author{
Ahmad $\mathrm{MAH}^{1}$, Abd Jalil IJ ${ }^{1}$, Nur Azah Binti Mohd Isa ${ }^{2}$, Nizamani SM ${ }^{3}$, Nasimullslam Mohd ${ }^{4}$ \\ ${ }^{1}$ MEMJ course, ${ }^{2}$ Lecturer, ${ }^{3}$ Associate Professor, ${ }^{4}$ Professor \\ ${ }^{1-4}$ Faculty of Medicine, Health Campus UiTM, Sungai Buloh, 47000 Selangor, Malaysia
}

\begin{abstract}
The health regulatory system in Malaysia is solely relying on complaints made by members of the public which mean a legal intervention is required in a case of medical negligence. Based on the number of claims and medical negligence cases reported in Malaysia, legal issues pertaining to medical practice have become a profound concern by medical doctors. Legal issues in medical practice are circulating in various aspects of care which comprise consent, confidentiality, doctor-patient relationship, documentation or record keeping and many others. There will be positive and negative implications congruent with these legal issues in medical practice. One of the negative implications is the medical doctors will unconsciously practice defensive medicine due to fear of impending medical litigation. On the other hand, due to the fear of impending medical litigation, medical doctors will become more aware and concern about the legal issues in medical practice. As a result, they will continuously improve their practice, quality of care which leads them to be more confident in practicing medicine.
\end{abstract}

Keywords: Legal Issues, Medical Practice, Medical Issues, Malaysia.

Int J Eth Trauma Victimology (2021). DOI: 10.18099/ijetv.v7i01.6

\section{INTRODUCTION}

$\mathrm{M}$ alaysia has a dual system of healthcare services that is government and private healthcare services. In the government sector, healthcare services are governed by the Ministry of Health $(\mathrm{MOH})$ which include a range of activities and responsibilities from treatment, promotion, rehabilitation to medical research. National health policies and major decisions on resourceallocations are under the jurisdiction of the $\mathrm{MOH}$. Meanwhile, these policies, and the operational managementof the medical, pharmaceuticaland dental services, as well as quality assurance,are delegated to State Directors of Health who are accountable to the Minister of Health at the central level. On the other hand, in relation to the private sector, the Private Healthcare Facilities and Services Act (PHFSA) 1998 was introduced by the government to regulate and control private health providers in complying to the standards of medical and health-related services.

Apart from the $\mathrm{MOH}$, there are several regulating bodies in Malaysia such as the Malaysian Medical Council (MMC) and the Malaysian Medical Association (MMA). The primary functions of the MMC are to register medical doctors intending to practise in Malaysia and to ensure the standard of practice is acceptable and reasonable(Malaysian Medical Council (MMC), 1987). Meanwhile, the MMA is a professional representative body of the medical doctors with its main objectives are to promote the interest of the profession of medicine and to assist in maintaining the professional standards of medical ethics (Malaysian Medical Association (MMA), 1997). Apart from these three bodies, there are other entities which also involved in regulating the Malaysia healthcare services such as Medico-legal Society of Malaysia (MLSM) (Rosnah \& Abdullah, 2017).

The health regulatory system is primarily governed by the following sources: the Federal Constitution, Acts of Parliament,
Corresponding Author: Mohammed Nasimul Islam, Professor of Forensic Medicine, Faculty of Medicine, Health Campus UiTM, Sungai Buloh, 47000 Selangor, Malaysia., e-mail: nasimul@uitm. edu.my

How to cite this article: Ahmad MAH, Abd Jalil IJ, Mohd Isa NAB, Nizamani SM, Nasimullslam M. Legal Issues in Medical Practice in Malaysia. Int J Eth Trauma Victimology. 2021;7(1):29-34.

Source of support: Nil

Conflict of interest: None

Received: 11/03/2021;

Accepted:27/05/2021;

Received in revised form: 20/05/2021; Published:25/06/2021

judicial decisions, the Penal Code (which is the primary source of criminal law in Malaysia) and guidelines and circulars issued by the $\mathrm{MOH}$, the MMC and the Director-General of Health. Apart from that, Malaysia's legal systems are designed and influenced by English common law (Choong, 2012). By virtue of Section 3 of the Civil Law Act 1956, Malaysia courts are allowed to apply the English common law and the rules of equity as administered in the English countries, however, only for matters that are not explicitly provided for by those sources mentioned earlier. Besides that, Malaysian judges have alsomade referencesto judgments passed in other Commonwealth jurisdiction as well (Choong, 2012). Nevertheless, the health regulatory system is solely relying on complaints made by members of the public which mean a legal intervention is required in a case of medical negligence. The intervention of law in the area of medical practice raises convoluted legal issues, which most of the time co-exist with ethical and religious dilemmas.

Based on the number of claims and medical negligence cases reported in Malaysia, legal issues pertaining to medical practice have become a profound concern by medical doctors (Hambali \& Khodapanahandeh, 2014). Due to the 
facts that legal issues in medical practice are relatively new in Malaysia, thus, there has been a lack of comprehensive data or statistics available in this area. However, referring to other indicators such as the compulsory requirement of indemnity subscription by medical doctors in order to renew their Annual Practice Certificates (APCs), amount of damages awarded by the court and rise in premium paid by medical doctors for protection against malpractice suits, support the allegation that there is increasing in trends on medical negligence cases in Malaysia (Radakrishan, 2003). Furthermore, according to the annual report published by the $\mathrm{MOH}$, there is also an upsurge in the amount of compensation paid for medical negligence ranging from RM1.2 million in 2006 to RM 20.1 million in 2015 and RM13.4 million in 2017 (Ministry of Health $(\mathrm{MOH})$ Malaysia, 2017).Legal issues in medical practice are circulating in various aspects of care which comprise consent, confidentiality, doctor-patient relationship, documentation or record keeping and many others.

\section{Research Methods}

This study was conducted using a library-based research method which includes the analysis of the primary sources (i.e legislation, law cases and guidelines), and secondary sources from Malaysia. This study examines the existing legal practice in Malaysia and the approach involves both conceptual and argumentative analysis on explored theories and precedented judicial decisions. The case law, articles and journals will be searched via google scholar and online databases such as LexisNexis, Hein Online, BM Journal, PubMed, Scopus, Wiley Online Library, Science Direct, and CLJ Law. All journals that are published in Malay and English language without any limitation of publication period will also be included in this study. All the legal and ethical issues involve individuals below the age of maturity (below 18 years old) will be excluded from this study.

\section{Discussion}

\section{Consent}

The MMC Guideline on Consent states that any medical interventions including any examinations, procedures, treatments and research, require valid consent from patients. For that reason, consent is regarded as a fundamental prerequisite in a doctor-patient relationship (Malaysian Medical Council, 2016). Consent with regard to medical practice is defined as an agreement or permission from a patient to the attending medical doctor to conduct any necessary investigations in order to diagnose and to treat the patient (Tengku Zainuddin, Abdul Rahim, \& Rajamanickam, 2015). Concept of consent was introduced in the western countries as early as eighteen century through the case of Slater $v$ Baker and Stapleton[1967] and the concept has evolved significantly since then. Having said that, only in 1957 the doctrine of informed consent was accentuated formally into the legal and medical practice(Beauchamp, 2011). Informed consent is also founded by the ethical principle of respect for patients autonomy (Beauchamp \& Childress, 2009). The legal issues with regard to informed consent are frequently focusing on the disclosure of information. A patient who has the capacity to make a medical decision will determine whether to accept or refuse the proposed treatment based on the information disclosed by his medical doctor (A K Abdul Hamid, 2002; Beauchamp, 2011).

\section{Disclosure of Information}

Failure to disclose information is one of many legal issues in medical practice which may affect the validity of consent significantly to the extent that failure of disclosing relevant information may render even a written consent invalid (Jackson, 2016). It is worth note-taking, that without valid consent, a medical procedure or an operation performed by a highly-skilled surgeon may overturn into an assault or battery instead as seen in the case (Jackson, 2016; Kassim, 2008). Similarly in Malaysia, failure to disclose information which deemed to be material to a patient may hold a doctor liable for breachof duty (Tengku Zainudin, Che Ngah, Abdul Rahim, \& Mohd Shariff, 2012). As a consequence, the patient may bring the doctor a legal action under the law of torts (P N Jahn Kassim, 2008; Malaysian Medical Council, 2016).

This is exemplified in the case of Tan Ah Kau v Government of Malaysia[1995], where the court decided that the surgeon was negligent for the failure of disclosing the risk of immediate postoperative paralysis. As a result, the two consent forms which were signed by the patient were concluded as invalid. In this case, the patient was suffered from a prolapsed disc due to a slow progressive low-grade astrocytoma. The patient was asked to sign two blank forms without information on the risk of paralysis, the differential diagnosis of a prolapsed disc and the histopathological findings. As testified by the expert witness, in this case, a patient with a low-grade astrocytoma would commonly have about 20 to 30 years to live before developing a paralysis which is often gradually in manner. Therefore, if this information were to be informed to the patient or in fact, most of the patients would decide to forego the surgery. The surgeon had clearly exercised his paternalistic approach through his failure of disclosing the relevant and necessary information as well as misconstrued that the two blank consent forms signed by the patient as the act of consenting to the proposed treatment. For that reason, it is incumbent on the medical doctors to provide adequate information to their patients even though the 'adequacy' index remains at a moot point.

Another example is the case of Foo Fio Na v Dr Sook Mun Foo \& Anor [2007] 1 MLJ 593.

In this case, the patient was involved in a motor vehicle accident (MVA) and was brought to the Assunta Hospital where she underwent two surgeries which resulted in total paralysis. The patient claimed that she was never informed about the risk of paralysis involved in both surgeries despite there was two consent attained from the patient during her admission at the Assunta Hospital. The first consent which was claimed to be given by the patient at the emergency department did not encompass the purpose of the first surgery and at the time, 
the patient was being assured by the doctor that it was only a minor procedure. Meanwhile, the second consent was a consent form on which the patient's thumbprint was affixed while the patient was totally paralysed and without any witness. Under those circumstances, the judge concluded that the surgeon was negligent in providing advice to the patient on the inherent and material risks of the proposed surgery, and both consents were rendered to be not valid. The judgment was then followed by the case of Dominic Puthucheary\&Ors v Dr Goon Siew Fong $\&$ Anor [2007] 5 MLJ 552 and many other cases.

\section{Spousal Consent}

The theory of autonomy advocated by the western countries conventionally endorses an independent role of a patient as an individual in making a medical decision for himself in his best interest (Dochin, 2001).Whereas, realistically, patients are individuals who are living with inter-dependent relationships and prominently in a familial, multicultural, and multireligious such as Malaysia. Thus, in the process of obtaining informed consent from a patient, the role (i.e. as a spouse, parents, or a child) and responsibility of which the patient might hold in the patient's life should be taken into the medical doctor (Lin, Kan, \& Chen, 2012).

For example, in the case of Gurmit Kaur v Tung Shin Hospital \& Anor [2012] 4 MLJ 260, the court has acknowledged the role of spousal in giving consent to reproductive surgery. In this case, the patient was a mother of four children was referred to the medical doctor for a cervical polyp which caused the patient to suffer from prolonged menstrual bleeding and pain. Upon scan, the medical doctor realized the patient's uterus was enlarged due to a fibroid and offered the patient a hysterectomy. The patient claimed that she persistently informed the medical doctor about her plan to conceive again. Having said that, the patient underwent the proposed surgery which she thought was a surgery to remove her fibroid and to stop the bleeding. During her follow up with the medical doctor and upon asking about when she could conceive again, that she was informed that the medical doctor had removed her uterus and she will not be able to conceive at all. In this case, the court held that the medical doctor was negligent and liable to disclose the information pertaining to the nature of the hysterectomy (i.e. removal of a uterus). The court also emphasized that it was the duty of the medical doctor to get the patient's husband to consent as the nature of the hysterectomy (i.e. reproductive surgery) and as required by the hospital's consent form.

In addition to the above case, the case of Abdul Razak v Raja Badrul Hisham \&Ors[2013]10 MLJ 34, the spousal consent has been extended to a non-reproductive surgery.In this case, the patient was diagnosed with intestinal obstruction and was referred to the surgeon which he offered to the patientfor emergency surgery.The patient refused to a Ryle's' tube insertion and as a result, the patient died due to aspiration pneumonia which could be prevented by inserting the Ryle's' tube. The court held that the surgeon was negligent due to failure of disclosing the risk of death to the patient and her husband as well as the court has recognized that the patient's spouse to be an authorized person who has the capacity to consent on behalf of the patient. In facts, prior to the surgery, the patient was claimed to be dependent on and had always delegated her autonomy in making medical decisions to her spouse. Furthermore, the patient's husband admitted that, if he was informed about the risk of death, he would have not proceeded with the surgery or would try to persuade and convince the patient to insert the Ryle's tube.

\section{Confidentiality}

The principle of confidentiality denotes the maintenance of privacy, by not sharing or divulging doctor-patient privileged or entrusted information to a third party (Ghalia, Amanullah, Zakariyah, \& Muhsin, 2018). Protection to private information affords confidentiality with unrestricted information and communication between a medical doctor and a patient. Therefore, diagnosis and treatment plans are based on the patients' preferences and wishes at the forefront. Confidentiality acknowledges respect for a patient's autonomy and encourages patients to instil their trust in medical doctors. The source of the obligation of confidentiality can be found in the common law in which deeply adopted by the Malaysian courts and various existing legislation and guidelines. Due to that, confidentiality is also one of the aspects of medical practice that has a probability of generating several challenging conflicts and legal issues. Having said that, confidentiality is neither absolute rights of patients nor the unconditional duties of medical doctors as there are circumstances where breaching of confidentiality is permissible according to the MMC's Guidelines on Confidentiality and legal precedents of the Malaysian courts.

The disclosure of a patient's medical information may result in more harm to the patient physically or psychologically, for example, termination of employment. The disclosure may pose a threat to the patient's intellect or his family, for example, divorce, inheritance or even lineage (Ghalia et al., 2018). In the context of Malaysia, the repercussion will be greater as the community is more family-oriented with social order. For those reasons, confidentiality should not be breached lightly except after considering and exploring all other avenues and implications of sharing the information (Peterson, 2018). Family members, relatives, friends and media are often requesting information about patients' medical conditions (Lo $\mathrm{B}, 2013)$. For certain patients, a consultation with the presence of his family members and relatives is requested by the patients themselves in where disclosing the patient's medical information is compelling (Beauchamp, 2011). At the same time, there are patients who refuse to disclose their medical information with their spouses, family members and children. Therefore, a medical doctor should always evaluate the whole circumstances and make their own judgement whether breaching of confidentiality is appropriate and permissible or there are any legal issues attached with a possible impending legal suit for medical negligence. Although parameters of 
confidentiality may differ according to jurisdiction and medical practice (i.e. forensic, pediatric or others), there are five commonly practiced exception in other countries where breaching confidentiality are permissible (Merideth, 2007):

a. Patient consents

b. Court order

c. Referral

d. Mandatory by the law.

e. Public interest or duty to a third-party

Meanwhile, according to Section 3 of the MMC Guideline on Confidentiality disclosure on confidential information are permissible under the three following circumstances:

a. when the law requires disclosure;

b. when the patient consents; or

c. to protect the public interest.

The similarities lie on the patient's consent, legal obligation and public interest. Here, the medical doctor's decision revolves around his understanding of circumstances as a whole and conviction towards the benefits of himself, patient, third party and the public. For example, during this Covid-19 pandemic, breaching of confidentiality about a patient's positive Covid-19 test has become an obligation and a legal duty of the medical doctor on the grounds of public interest.

Breaching of confidentiality without consent from the patient was recently illustrated in the case of Lee Ewe Pohv Dr Lim Teik Man and Another [2011] 4 CLJ 397.This case involved a female patient who underwent a procedure called Stapler Haemorrhoidectomy, whose a photograph of her intimate partwas taken by the surgeon while she was under anesthetic. The photographs were a reference for pre and post-procedure which was for documentation purposes, however, without the patient's knowledge and consent. The court ruled that the surgeon was liable for breaching confidentiality despite his explanation that such practice was in accordance with accepted medical practice and merely to facilitate his explanation to the patient during the follow-up. The court also justified that the breach of confidentiality was also on the grounds that there is publication involved to the fact the hospital nurse was able to access such confidential information. Although in the case, there was no direct evidence that the photographs had been disseminated by the surgeon for other malicious reasons. Although the facts of this case are exceptional, the case also highlights the significance of consent before taking any images of patients unless in situations where photographs are absolutely necessary and there is no opportunity to seek for the patient's consent.

\section{Documentation}

Till up to date, majority of government hospitals in Malaysia are still operating via the conventional method where they are still using paper-based medical records(Ariffin, Ismail, Kadir, \& Kama, 2018). A good documentation practice (GMP) whether handwritten or electronic is vital in ensuring the continuity of care as adequate documentation enable medical doctors to reconstruct their management and treatments plans at any time without solely rely on their memory(The Medical
Protection Society, 2014). Besides that, the documentation should also, therefore, be comprehensive and adequate to allow another medical doctor either who isalso treating the patient to carry out previous plans or seeing the patient upon a referral. For that reason, GMP is one of the elementsthat constitutea good medical practice(Malaysian Medical Council, 2006). Documentation or medical records may also be required for legal purposes, for example, as evidentiary documents during court proceedings and most of the time will influence the court's judgement over medical negligence litigation. This has been shown in those cases discussed previously which involved inadequate documentation, or incomplete consent forms (see Gurmit Kaur v Tung Shin Hospital \& Anor [2012] and Abdul Razak v Raja Badrul Hisham \& Ors [2013]).

\section{Consent Form}

A requirement for written consent has been enacted in Regulation 47(3) Part VIII of the Private Healthcare Facilities And Services Regulations 2006, which requires all private hospitals (in Malaysia this is also applicable to government hospitals)to incorporate consent form into their standard operating procedure (SOP) and routine documentation. As mentioned formerly, consent form has substantive evidentiary value in medical litigation apart from a tool to obtain informed consent from patients. Nonetheless, the consent form may still observe as inadequate, hence, disputable even though the form is embodied with the patient's signature (Ngah, 2005). It is being argued consistently by medical doctors pertaining to the inconclusive of information that should be written on the consent form. The reason for such argument is in medical practice, it is unrealistic to include all information in a form, and at the same time, the provision of information written in the consent form will still provide minimal protection to the medical doctor in charge (Ngah, 2005).

\section{Medical Records}

A medical record is a primary document which contains all medical information of a patient and recorded by a medical doctor or other healthcare workers(Malaysian Medical Council, 2006). By virtue of Regulation 44(1) of the Private Healthcare Facilities and Services Regulations 2006 states that "A patient's medical record is the property of a private healthcare facility or service", however, a medical doctor should still obtain the patient's consent before sharing or disclosing information, or medical report/record to a third party except in certain circumstance as hitherto mentioned here. Therefore, any discussion and decision by the patient, in regard to whom the information or medical report/record may be released must be documented in the medical record which includes the patient's wishes of non-disclosure at any time, even after death, must also be recorded. Non-compliance of failure to adhere to this practice may render a medical record as adverse evidence towards medical doctors in a medical negligence suit. It is worth pointing out that audio and visual recordings also form a part of the patient's medical record. They are therefore subject to similar expectations regarding confidentiality and consent. 
In medical negligence litigation or a complaint, a medical record is essential documentary evidence for both medical doctors and patients (Mokhtar, 2020).In the event of errors or negligence by a medical doctor who has treated a patient, the medical doctor may encounter civil action from the patient claiming for damages from the court( Kassim, 2007). On one hand, a patient's medical record is most likely the substantial evidence that can defend the medical doctor and the hospital for vicarious liability. The copy of the medical record would be registered as evidence of that case and ironically, at the same time, the medical record would be used by the patient's lawyer as evidence of negligence. On top of that, the patient's medical record will be the main source of information which must be referred by the medical doctor in supporting his statement(Govindasamy, 2017). Subsequently, the testimony will be in accordance with the information stipulated in the medical record as evidence in the court. Therefore, adequacy, accuracy and clarity of the medical record serve a significant key role in determining the decision of the court besides the witnesses(Govindasamy, 2017).

Another legal issue in medical practice (specifically in forensic medicine) which related to criminal cases (for example, murders, assault or rapes)all particular of crimes must be documented by the examining medical doctor or the forensic specialist(MOH, 2015). They are required to document or record their findings meticulously based on their examination on the victim in the medical record which will be submitted to the local authorities for further investigations or as evidence in a criminal proceeding(Govindasamy, 2017; MOH, 2015). All findings sometimes act as a leading clue to capture or to initiate a criminal charge against the perpetrator if a hearing is required.

\section{Conclusion}

There are many other legal issues in medical practice that has emerged at this recent time such as related to telemedicine, clinical trials, vaccination and competency. Telemedicine has slowly become the preferred delivery of healthcare services and enormous legal issues attached to this online consultation are still novel and unclear (Abdul, 2010). Further studies on telemedicine and those mentioned previously and recommendation of solutions which correspond to Malaysia's healthcare setting are necessary.

There will be positive and negative implications congruent with these legal issues in medical practice. One of the negative implications is the medical doctors will unconsciously practice defensive medicine due to fear of impending medical litigation. Subsequently, will discourage the medical doctors to assist patients or to get involved in the process of decisionmaking. On the other hand, due to the fear of impending medical litigation, medical doctors will become more aware and concern about the legal issues in medical practice. As a result, they will continuously improve their practice, quality of care which leads them to be more confident in practicing medicine. It is a fairly expectation of proactive role from patients due to vast exposure of health and medical information which is widely accessible. Medical doctors are still conceded greater responsibility in regard to the informed consent, confidentiality and documentation, however, that does not mean patients will be denied the rights to medical decisionmaking.

Informed consent may still be an ideal practice oran effective tool in promoting a shared-decision making which unites the medical paternalism and patients' autonomy. As discussed above, even where the public interest requires disclosure, it is paramount for medical doctors to confine the information to the extent strictly necessary. In other words, the fact that it is in the public interest to reveal even some aspects of a patient's medical condition does not justify disclosing all the detailsat all. As for genetic information concerns both the patients involved and their family members, which in turn, produce a legal conflict and issue between the doctors' duty to uphold patient's confidentiality and their general duty to protect the public interest. While it is important to preserve patients' confidentiality, medical doctors should also consider informing patients' family members suffering from genetic diseases as such information may be impacted their future health and life profoundly.

Medical doctors should always provide a safe environment and assurance to patients during the consultations. With that, patients would become more transparent, engaging and expressing with regard to their concerns and expectation to their medical doctors. A clearly expressed expectation between a patient and a doctor is important to ensure effective communication which builds a strong doctor-patient relationship. As a conclusion, it is necessary to balance between the legal issues and their implications towards medical practice. A doctor-patient relationship should also constitute honesty, trust, understanding and effective communication. Effective communication required good communication skill from medical doctors as it will contribute greatly to the success of informed consent.

\section{REFERENCES}

\section{Case Law}

1. Abdul Razak bin Datuk Abu Samah (claimed as a widower to Fatimah@Rohanibt Zainal, on behalf of the deceased)v Raja Badrul Hisham bin Raja Zezeman Shah \&Ors [2013] 10 MLJ

2. Foo Fio Na v Dr Sook Mun Foo Anor [2007] 1 MLJ 593

3. Gurmit Kaur v Tung Shin Hospital \& Anor [2012] 4 MLJ 260

4. Slater v Baker [1767] 2 WilsKb 359, 95 Er 860

5. Tan Ah Kau v The Government Of Malaysia [1995] MLJU 183

6. Tarasoff $v$ Regents of the University of California (1976) 551 $\mathrm{P} 2 \mathrm{~d} 334$,

7. Wv Edgell [1990] 1 All ER 835.

\section{Legislation}

8. Private Healthcare Facilities and Services Regulation 2006. 


\section{Journals}

9. Hamid AA. How much should doctors tell their patients?. Med J Malaysia. 2002 Jun;57(2):133-135.

10. Abdul TF. Ethical and legal issues in telemedicine: prospects and challenges (Master's thesis, Kuala Lumpur: Ahmad Ibrahim Kulliyyah of Laws, International Islamic University Malaysia, 2010).

11. Beauchamp TL. Informed consent: its history, meaning, and present challenges. Cambridge Quarterly of Healthcare Ethics. 2011 Oct;20(4):515-523. doi:10.1017/S0963180111000259

12. Beauchamp T L, Childress JF. Respect for Autonomy. In Principles of Biomedical Ethics (6th ed., pp. 99-148). New York: Oxford University Express. 2009.

13. Ngah AC. Informed consent in Malaysia: an overview. Journal International de Bioéthique. 2005;16(1):143-161. doi:10.3917/ jib.161.0143

14. Choong KA. Malaysia. Medical Law, United Kingdom. 2012.

15. Dochin A. Understanding autonomy relationally: toward a reconfiguration of bioethics principles. J Med Philos. 2001;26:368-374.

16. Ghalia B, Amanullah M, Zakariyah L, Muhsin SM. Medical Ethics in the Light of Maqāșid Al-Sharī'ah: A Case Study of Medical Confidentiality. Intellectual Discourse. 2018 Jun 12;26(1):133-160.

17. Govindasamy K. Medical Records From The Perspective Of Medico Legal. 2017. Retrieved from http://www.myhealth.gov. my/en/medical-records-perspective-medico-legal/

18. Hambali SN, Khodapanahandeh S. A review of medical malpractice issues in Malaysia under tort litigation system. Glob J Health Sci. 2014;6(4), 76-83. doi:10.5539/gjhs.v6n4p76

19. Jackson E. Medical Law: Text, Cases, and Materials: Oxford University Press. 2016.

20. Jahn Kassim PN. Medical negligence litigation in Malaysia. 2007.

21. Jahn Kassim PN. Medical Negligence Law in Malaysia. Petaling Jaya, Malaysia: International Law Book Services. 2008.

22. Lin ML, Kan WM, Chen CH. Patients' perceptions and expectations of family participation in the informed consent process of elective surgery in taiwan. Asian Nurs Res (Korean Soc Nurs Sci). 2012;6(2):55-59. doi:10.1016/j.anr.2012.05.001
23. Lo B. Resolving Ethical Dilemmas A Guide for Clinicians. 2013. 24. The Constitution, Articles and By-Laws, 1997.

25. Guideline on Medical Records and Medical Reports, 2006.

26. Malaysian Medical Council. Malaysian Medical Council Guideline: Consent for Treatment of Patients by Registered Medical Practitioners. 14. 2016.

27. Code of Professional Conduct. 1987.

28. Merideth P. The Five C's of Confidentiality and How to DEAL with Them. Psychiatry (Edgmont). 2007 Feb 1;4(2):28.

29. Ministry of Health (MOH) Malaysia. Annual Report 2017. 2017. Retrieved from Putrajaya:

30. One Stop Crisis Centre: Policy and Guidelines for Hospitals, 2015.

31. Mokhtar MF. The Law and Challenges to Access Medical Record for Medical Negligence Claims in Malaysia. Jurnal Undangundang dan Masyarakat. 2020 Sep 1;26:43-50. doi:10.17576/ juum-2020-26-05

32. Ariffin NA, Ismail AK, Kadir IK, Kamal J. Implementation of electronic medical records in developing countries: challenges \& barriers. Int J Acad Res Prog Educ Dev. 2018;7:187-199. doi:10.6007/IJARPED/v7-i3/4358

33. Peterson JL. Confidentiality in medicine: how far should doctors prioritise the confidentiality of the individual they are treating? Postgraduate medical journal. 2018 Oct 1;94(1116):596-600. doi:10.1136/postgradmedj-2018-136038

34. Rosnah N, Abdullah W. Medical Regulation in Malaysia: Towards an Effective Regulatory Regime. Policy and Society. 2002 Jan 1;21(1):96-124.. doi:10.1016/s1449-4035(02)70005-2

35. Zainudin TN, Rahim AA, Rajamanickam R. Consent to medical treatment and the autonomous power of adult patients: The Malaysian legal position. Mediterranean Journal of Social Sciences. 2015 Aug 18;6(4):418. doi:10.5901/mjss.2015. v6n4s3p418

36. Zainudin TN, Anisah CN, Rahim AA, Shariff AA. The meaning of a valid consent to medical treatment in Malaysia: Tan Ah Kau V Government of Malaysia revisited. Pertanika J Soc Sci Human. 2012 Jun 1;20:35-42.

37. The Medical Protection Society (Producer). Medical Records. 2014. 